\title{
PSYCHIATRIC ILLNESS IN THOSE ENGAGED TO BE MARRIED
}

BY

\author{
D. L. DAVIES \\ From the Maudsley Hospital, London
}

Savage (1888) described a number of patients suffering from what he called "mental disorders associated with marriage engagements". In so doing he drew attention to the aetiological importance of sexual tension deriving from the engagement situation and hysterical personality traits in those affected. Janet (1903a), in referring to some dozen cases of this kind within his personal experience, agreed with Savage in the main, though attributing less significance to the sexual aspect and more to the personality of these patients, whom he regarded as psychasthenics.

It is proposed in this study to use data available from patients of this kind to try to throw more light on the origins, course, and outcome of this condition, which is characterized by anxiety, depression, and doubt about the engagement, beginning in those who are engaged to be married. In this connexion the term "engaged" is used to include "not only those formally engaged, but also those with an informal but definite understanding that they would be married at some future date" (Burgess and Wallin, 1953a). In order to avoid a cumbersome repetition of words it is proposed to employ the

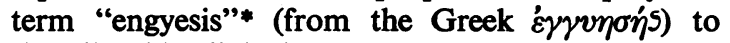
describe this clinical condition.

*I am indebted to Dr. C. P. Blacker for suggesting this term.

\section{MATERIAL}

In all, fifty cases were seen at the Maudsley Hospital, all but ten of which came under the care of the writer. Patients displaying engyesis when seen numbered 48 , and two other patients admitted for some other condition gave clear histories of attacks of this kind earlier in life.

Of the $\mathbf{4 8}$ active cases, thirty men and one woman were in-patients, and nine men and eight women were outpatients. Some clinical details of the whole group are set out in Table $I$.

\section{RESUlts}

The predominant symptoms in all cases were anxiety and depression. Insomnia, loss of appetite and weight, headaches, feelings of "tension", and lack of concentration were especially marked. Indecision about the marriage was very prominent in these patients. Other symptoms noted in certain cases were phobias (specially of travel or of going mad), unreality feelings, and asthma (two cases). In two patients, who showed also some ideas of reference and delusions of persecution, there was a history of previous illness in which these features had been manifest. The clinical picture was closely comparable to that described by Savage (1888) and Janet (1924).

TABLE I

CIVIL STATUS, FREQUENCY OF ATTACKS, AND AGE AT FIRST ATTACK, OF FIFTY ENGYETIC PATIENTS

\begin{tabular}{|c|c|c|c|c|c|c|c|c|c|c|c|c|c|c|}
\hline \multirow[t]{2}{*}{ Sex } & \multirow[t]{2}{*}{ Civil Status } & \multicolumn{3}{|c|}{$\begin{array}{l}\text { Frequency } \\
\text { of Attacks }\end{array}$} & \multicolumn{9}{|c|}{ Age at First Attack (yrs) } & \multirow{2}{*}{ Total } \\
\hline & & 1 & 2 & $3+$ & Under 21 & $22-25$ & $26-30$ & $31-35$ & $36-40$ & $41-45$ & $46-50$ & $51-55$ & over 56 & \\
\hline Male & $\begin{array}{l}\text { Bachelors } \\
\text { Divorced Men } \\
\text { Widowers }\end{array}$ & $\begin{array}{r}22 \\
2 \\
3\end{array}$ & $\begin{array}{l}10 \\
-\end{array}$ & $\frac{3}{-}$ & $=$ & $\begin{array}{l}16 \\
-\end{array}$ & $\frac{8}{-}$ & $\frac{5}{-}$ & $\frac{3}{-}$ & $\begin{array}{l}1 \\
1 \\
-\end{array}$ & $\bar{z}$ & $\begin{array}{l}1 \\
1 \\
2\end{array}$ & $\overline{\overline{1}}$ & $\begin{array}{r}35 \\
2 \\
3\end{array}$ \\
\hline Female & $\begin{array}{l}\text { Spinsters } \\
\text { Divorced Women } \\
\text { Widows.. } \quad . .\end{array}$ & $\frac{7}{-}$ & $\frac{3}{-}$ & $=$ & $\begin{array}{l}1 \\
-\end{array}$ & $\frac{6}{-}$ & $\frac{1}{-}$ & $\frac{1}{-}$ & $\begin{array}{l}1 \\
-\end{array}$ & $\bar{z}$ & $=$ & $\bar{z}$ & $\bar{z}$ & $\begin{array}{l}10 \\
-\end{array}$ \\
\hline Total & .. & 34 & 13 & 3 & 2 & 22 & 9 & 6 & 4 & 2 & - & 4 & 1 & 50 \\
\hline
\end{tabular}


The onset of symptoms in relation to the engagement was variable, as Janet (1903a) had noted. In some cases the symptoms began insidiously early in the engagement and built up steadily. It was noticed, however, that in other cases the illness suddenly began very soon (often a matter of days or hours) after the occurrence of some event on which the marriage date hinged. Booking a hall for the wedding reception, or finding a flat to live in, were examples of events of this kind. Freud (1918), dwelling on this phenomenon, attached special significance to the onset of the illness in relation to the removal of an external prohibition which had previously rendered any internal conflict needless. In other cases, where the marriage was to be linked to success in an examination or promotion at work, the symptoms began in relation to these events and the anxiety shown was often displaced thereon.

The symptoms were almost always displayed to the healthy partner, the patient's attitude being best summarized in the words, "You can see how ill I am. It would not be fair to you to go on with the marriage". The invariable response of the healthy partner could be summed up in the words "I love you, and will stand by you". At this point the patient's symptoms became worse, and this usually was the stage at which he (or she) was seen by the psychiatrist.

Attention is directed to some of the factors associated with this kind of illness, as evident from the clinical material which has been examined:

(a) Sex.-The preponderance of males (30 out of 31 ) in the in-patient group has no special significance, but arises from the fact that the writer's beds are all in the male wards. A fairer index of sex distribution is obtained from the out-patient group, where the bed factor does not operate. Of this group of seventeen patients, nine were men and eight women. Of male in-patients six had come through the writer's Out-patient Clinic, in respect of which therefore the figures become fifteen men and seven women.

(b) Age.-The youngest patient was a girl aged 18, the oldest a man aged 71 . Of the fifty patients, 31 (62 per cent.) were 20-30 years of age at the time of the first attack, and 37 (72 per cent.) were aged between 20 and 35 . As several patients were seen only at a subsequent attack the average age of patients when seen was rather higher than is shown. This point is made because Savage (1888) reported that the majority of his patients were over 30 years of age when seen.

The divorced men and widowers were all aged 44 or over, whilst the great majority of the bachelors and spinsters (43 out of 45 ) were aged 40 years or under.

(c) Civil Status.-No divorced women or widows appear in the group. Savage (1888) said he had never seen widows or widowers affected, but three widowers appear in the present series. It must be tentatively concluded that women who have been married are unlikely to become ill in this way.

(d) Frequency of Attacks.-Of the fifty patients, sixteen ( 32 per cent.) had more than one attack, and three ( 6 per cent.) had three or more. The frequency of broken engagements without engyesis was even higher. This tendency to repeated breakdown in subsequent engagements was noted by Savage (1888), and Janet (1924) recorded the case of a woman whom he saw in her sixth engagement-illness.

(e) Stress.-There was very little evidence of especial stress apart from the engagement situation. Three men were working for examinations, in three cases there were religious differences between the engaged pairs but little to suggest that these were of any great concern, one woman feared she might be pregnant, and the fiancee of another patient had been recommended for a breast operation. The nature of these stresses and the attitude towards them of the patients suggested that they played $a_{0}$ relatively unimportant part in the aetiology of the illness.

The role played by sexual tension, to which Savage (1888) attached importance, is not easy to evaluate. In eleven of the fifty patients no information on this point was forthcoming. In the remaining 39 patients, however, it was found that two were cohabiting, sixteen were having frequent sexual intercourse, and 21 were chaste. It would seem that in nearly half of the cases where information was available, sexual tension could not be playing any large part.

There were only two cases where sexual activity was volunteered as a cause of anxiety. One of these was an effeminate man who knew himself to be impotent, the other a young woman who was very ignorant of sex and thought she might be pregnant though a virgin.

(f) Previous Psychiatric Illness.-Excluding previous attacks of engyesis, twenty out of the fifty patients (40 per cent.) gave a history of a clear-cut psychiatric illness for which they had sought medical advice. Depression, anxiety, hypochondriasis, and "black-outs" seemed to be the chief symptoms of which they had earlier made complaint. Two patients were liable to attacks of asthma. In one of these asthma was a presenting symptom followed later by anxiety; the other, a man who had three attacks of 
engyesis, presented with asthma in one instance and anxiety symptoms in the other two.

(g) Previous Personality.-The frequency of recurrent attacks in certain individuals and the high rate of previous psychiatric illness point to the possible aetiological role of personality factors in these patients Savage (1888) thought hysterical traits were present. Raymond and Janet (1903) regarded these people as psychasthenics, with indecision as a prominent character trait.

An attempt was made to rate these patients with regard to certain personality traits on the basis of a full history. The trait looked for was scored as present only if it was a prominent feature of the previous personality. In this way the conclusion was reached that 21 out of 33 (63 per cent.) were especially obsessional, thirteen out of 29 (45 per cent.) were especially indecisive, and fifteen out of 25 (60 per cent.) were especially dependant upon their mothers. In the absence of any control group, no conclusions should be drawn from these figures, but they may act as pointers in further investigations.

(h) Progress in Hospital.- The thirty patients admitted to hospital comprised 29 men and one woman, and all but one of these have now been discharged. The reason for the preponderance of men has been given above. Presumably these patients were more severely ill, in the main, than those who remained out-patients. Reference to their case records shows that six patients ( 20 per cent.) were regarded as suicidal at some time during their stay.

In some cases patients were selected for in-patient treatment because there were few signs that the hesitation about the engagement situation would resolve while they remained out-patients. The mere act of admission seemed sometimes to clarify the situation, the healthy partner breaking off the engagement in the belief that the patient was now "mental". The engagements of eleven patients (38 per cent. of the discharged in-patients) were broken in hospital. An equal number of engagements was confirmed while the patient was in hospital. In every case but one, as shown in Table II, the engagement situation was clarified before discharge, and the resolution of doubt on this score was accompanied by marked improvement or recovery. Definitions of those terms as used here are given in Table II.

This removal of doubt regarding the engagement situation was not simply a manifestation of improvement, since there was clear evidence in nineteen cases that it antedated clinical improvement by a few days or weeks. Indeed, the impression was formed that discussions with the patient aimed at
TABLE II

CLINICAL STATE AT TIME OF DISCHARGE, WITH REFERENCE TO ENGAGEMENT SITUATION, OF 29 ENGYETIC IN-PATIENTS

\begin{tabular}{|c|c|c|c|c|}
\hline \multirow{2}{*}{ Engagement } & \multicolumn{3}{|c|}{ Clinical State } & \multirow[b]{2}{*}{ Total } \\
\hline & Unchanged & Improved* & Recovered & \\
\hline $\begin{array}{l}\text { Confirmed in } \\
\text { Hospital }\end{array}$ & - & 7 & $\dot{4}$ & 11 \\
\hline Broken in Hospital & - & 7 & 4 & 11 \\
\hline $\begin{array}{l}\text { Broken before } \\
\text { Admission }\end{array}$ & - & 3 & 3 & 6 \\
\hline Situation Unchanged & 1 & - & - & 1 \\
\hline Total & 1 & 17 & 11 & 29 \\
\hline
\end{tabular}

* "Improved" means able to leave hospital, to work, and to live a normal life with only minor discomfort from occasional symptoms which were not present before illness.

"Recovered" means complete restoration to pre-morbid state.

assisting him to clarify his mind regarding the engagement situation were therapeutically valuable. The fact that six patients, who later responded favourably, were admitted after breaking their engagements (Table II) shows that improvement may be delayed even after a firm decision about the engagement has been reached. It seemed, also, that admission to hospital justified the patient in his own mind when he subsequently broke the engagement, and some relief of persisting guilt feelings in this connexion was obtained where the admission to hospital occurred after the break, as in the group of six patients just mentioned.

Nine patients received electroplexy during their stay; the general impression was, however, that no more than temporary relief was afforded in this way, unless the engagement situation had also been clarified. The main treatment was directed to focusing the patient's thoughts on to his engagement so that he could arrive at a firm decision about it. It was important to avoid overt pressure in any direction. The partner was also interviewed as often as seemed desirable. Discussions of this kind usually resulted in a firm decision being made, in a way which left the couple satisfied that these had not been imposed by the therapist.

Not infrequently, the patient, having broken the engagement, would say that he was moving away from the district in which he had lived previously. This recalls the dictum of Savage (1888): "I know of no mental cases which benefit so much by sea voyages as these".

(i) Follow-up.-The difficulties of following the later progress of these patients are unusually great, because those whose engagements are broken often 
move away, as mentioned, while those who marry tend to change their address. However, it was possible to follow up a total of 33 patients for periods of from 6 months to 5 years. It may be of interest to divide these into two groups: those whose engagements were broken and those who married.

Those whose engagements were broken comprised seventeen men and one woman. Seven men were completely recovered. One of these died from natural causes during a subsequent engagement not marked by engyesis and another from this group met his ex-fiancee by accident in the street and became re-engaged to her. Five men were improved and were troubled but slightly by residual symptoms (e.g. dryness of the mouth, feelings of loneliness). Two others, one man and one woman, were comparatively unchanged when they became engaged to other partners. Three men had relapses in which they committed suicide. It would seem that the results were generally favourable in twelve out of eighteen ( 66 per cent).

Those who married comprised twelve men and six women. Included here are the three subjects mentioned in the preceding section who became reengaged (one man) or engaged to a different partner (one man; one woman). Of these twelve men, ten ( 83 per cent.) were found to be completely well at follow-up; one of these was the man who had become engaged again while still ill. Apart from one man who had slowly recovered in the course of a year or more, all reported that their improvement had begun immediately after marriage. It must be emphasized that the follow-up in some of these cases was less than one year, and only five years at most. What happened later in the marriage is not known, but two patients (a man who came under notice for depression at the age of 53 , and a woman who suffered a phobic illness at 40) gave histories of recurrent engyesis 23 and 21 years earlier. The man had been impotent throughout his married life. Of the two remaining men, one continued to be ill after he married, while the other became well on marriage but has frequently relapsed since.

Three of the women ( 50 per cent.) are quite well. The other three have shown a fluctuating illness requiring out-patient treatment after initial improvement on marriage. One of these is the asthmatic referred to earlier, who presents herself with this symptom or with headaches and anxiety. It would seem that the results were generally favourable in thirteen out of eighteen ( 72 per cent).

In view of the possibilities of later illness, it is of interest that those who marry (about half the group followed up) do as well as those who do not.

\section{Discussion}

"Love notwithstanding, most couples must anticipate a measure of stress as part of their courtship experience", wrote Burgess and Wallin (1953b). It is possible that psychiatrists have insufficiently appreciated the truth of this statement, whilst recognizing that other epochs of life, as for example the puerperium, may be especially stressful.

Social factors relating to engagement and marriage have changed considerably from Savage's day to our own. The sexes now mingle more freely, sexual topics are discussed more openly, marriage is no longer the career for which the well-bred girl is prepared to the exclusion of all others, and divorce is much more frequent. Yet the engagement period is still stressful and apt to be marred by psychiatric ill-health. As the incidence of engyesis has not been assessed, it is not possible to evaluate the role of changing social customs in the aetiology of this condition. One is therefore thrown back to a closer examination of the people who are involved, in the light of what is known from the studies of normal engaged couples.

Unfortunately, no such studies seem to have been carried out in this country. Burgess and Wallin (1953) have collected much valuable sociological and psychological information on engaged couples, mainly undergraduates and their friends in metropolitan Chicago. Though only the crudest comparisons may be made with this group, it would seem that engyetics might have contributed disproportionately to the $3 \cdot 1$ per cent of men and $4 \cdot 4$ per cent. of women whose health became impaired during engagement (Burgess and Wallin, 1953c), to those with low engagement success (Burgess and Wallin, 1953d), and especially to the group of broken engagements amounting to 50 per cent. in our patients as against 15 per cent. in the Chicago normals (Burgess and Wallin, 1953e). It would be interesting to see how far engyetics show the personality traits which Winch (1941) found to be important in the Burgess and Wallin study, as making for poor adjustment in engagement as well as in marriage. Questions of this kind must await fuller study, perhaps by questionnaire techniques, of a much bigger group than has been described here.

The early recognition of the condition here described may well fall to Marriage Guidance Clinics. Mudd and Preston (1950) report that, of clients consulting Marriage Counsellors at six selected clinics in the United States, the majority were aged 20 to 35 , about one-half to two-thirds were women, up to 66 per cent. were single, and one of the problems about which advice was sought was postponing the marriage or breaking the engagement. Some 
illustrative case histories of clients seen at their clinics closely reproduce the early attitude of most engyetics. There are reasons, it would seem, for believing that in the United States engyesis might occur in some ploportion of the clients of Marriage Counsellors, and that follow-up studies carried out in such clinics might contribute to our knowledge of morbidity from this cause.

The acute illness subsided more or less completely with broken engagement or marriage in most of the cases described here, but the persistence or recurrence of symptoms after marriage in 28 per cent. of our cases is bound to enjoin caution on those who might be tempted to recommend that step. Janet (1903b) expressed his firm view that the marriage should always be proscribed. It appears, however, that 72 per cent of these marriages in our series have turned out well so far. One should not be too pessimistic where the marriage goes through even against proffered advice, though the longest follow-up period in this series is only 5 years, and many cases were followed for a much shorter period.

\section{SUMmaRY}

(1) A study has been made of fifty patients manifesting psychiatric illness characterized by anxiety, depression, and doubt about the engagement, beginning in those who are engaged to be married. The term "engyesis" is used to designate this clinical picture.
(2) The condition occurs in both sexes, and is most common between the ages of 20 and 35 years. Bachelors and spinsters predominate. No case was encountered in women who had been divorced or widowed.

(3) The tendency to recurrent attacks in certain individuals, and the incidence of earlier neurosis in twenty ( 40 per cent.) of the fifty subjects, suggest that predisposing personality factors are important. Sexual frustration is unlikely to have much bearing on the origin of this condition.

(4) About half of the cases followed up for 6 months to 5 years married. About one-quarter of these subjects showed fluctuating ill-health afterwards, roughly the same proportion as in those who broke off their engagements.

\section{REFERENCES}

Burgess, E. W., and Wallin, P. (1953a). "Engagement and Marriage", p. 44. Lippincott, Chicago.

p. (1953b). Ibid., p. 265.

- (1953c). Ibid., p. 244.

- (1953c). Ibid., p. 244.

- (1953e). Ibid., p. 182.

Freud, S. (1918). "Sammlung kleiner Schriften zur Neurosenlehre". 4th ser., p. 527. Heller, Leipzig.

Janet, P. (1903a). "Les obsessions et la psychasthenie"., vol. 1, p. 627 Alcan, Paris.

(1903b). Ibid., vol. 1, p. 700.

(1924). "Névroses et idées fixes", 3rd ed., vol. 2, p. 87. Alcan, Paris.

Mudd, E. H., and Preston, M. G. (1950). In "Toward Family Stability", Ann. Amer. Acad. polit. soc. Sci., 272, 102.

Raymond, F., and Janet, P. (1903). "Les obsessions et la psychasthenie"., vol. 2, p. 278. Alcan, Paris

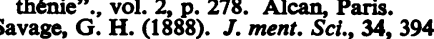

Winch, R. F. (1941). Amer. J. Sociol., 46, 686. 